\title{
A TRADUÇÃO DE UM POEMA DE STEPHEN CRANE
}

\section{Paulo Henriques Britto}

Resumo: $\mathrm{O}$ artigo analisa a tradução de um poema de Stephen Crane, feita por mim, e comenta a utilização, no texto traduzido, de recursos retóricos, lexicais e formais encontrados num poema de Castro Alves.

Palavras-chave: Stephen Crane; Castro Alves; tradução de poesia.

\section{War is kind}

Do not weep, maiden, for war is kind.

Because your lover threw wild hands toward the sky

And the affrighted steed ran on alone,

Do not weep.

War is kind.

Hoarse, booming drums of the regiment, Little souls who thirst for fight,

These men were born to drill and die.

The unexplained glory flies above them. Great is the battle-god, great, and his kingdom A field where a thousand corpses lie.

Do not weep, babe, for war is kind.

Because your father tumbled in the yellow trenches, Raged at his breast, gulped and died,

War is kind.

1 Poeta e professor associado na Pontifícia Universidad Católica do Rio de Janeiro (PUCRio) em cursos de tradução, criação literária e literatura brasileira: <phbritto@hotmail. com>. 
Remate de Males, Campinas-SP, v.38, n.2, pp. 620-63o, jul./dez. 2018 - 621

Swift blazing flag of the regiment, Eagle with crest of red and gold, These men were born to drill and die. Point for them the virtue of slaughter, Make plain to them the excellence of killing And a field where a thousand corpses lie.

Mother whose heart hung humble as a button On the bright splendid shroud of your son, Do not weep.

War is kind.

(CRANE, 1965, pp. 77-78)

\section{A guerra é boa}

Não chores, moça, que a guerra é boa.

Se teu amado ergueu aos céus as mãos em garra

E o corcel temeroso seguiu só,

Não chores.

A guerra é boa.

Rudes tambores roucos do regimento, Almas pequenas com sede de luta, Homens nascidos para a marcha e a morte. Acima deles paira a glória inexplicada. Um campo onde mil corpos apodrecem.

Não chores, criança, que a guerra é boa.

Se teu pai tombou numa trincheira parda, $\mathrm{O}$ peito ardente, arfante, e enfim morreu,

$15 \quad$ Não chores.

A guerra é boa.

Flamejante pendão do regimento, Águia feroz de aurirrubra crista, Homens nascidos para a marcha e a morte. Mostrai-lhes a virtude da matança, A excelência do assassinato E um campo onde mil corpos apodrecem.

Mãe, humilde em teu amor como um botão Na esplêndida mortalha de teu filho,

25 Não chores.

A guerra é boa.

(CRANE, 1990, tradução nossa) 
A reputação literária de Stephen Crane (1871-190o) baseia-se essencialmente na sua ficção, tendo como referência principal The Red Badge of Courage, romance de guerra que se tornou um clássico. Em sua curta carreira, Crane produziu outros romances e um punhado de contos que logo entraram para o cânone literário norte-americano. Já sua pequena produção poética teve bem menos repercussão. "War is kind" é o único de seus poemas que se tornou conhecido, sendo incluído em inúmeras antologias.

"War is kind" destoa da maior parte da poesia de Crane sob mais de um aspecto. O típico poema desse autor é bem breve, em versos livres, tem uma ou duas estrofes apenas, é desprovido de título e concentra-se numa única imagem. Jean Cazemajou (1969, p. 35), citando o poeta Carl Sandburg, chega a afirmar que a poesia de Crane "por vezes prenuncia o imagismo" - muito embora Crane, até onde sei, não seja nunca mencionado por Ezra Pound e pelos outros poetas ligados às vanguardas do início do século. $\mathrm{O}$ que me parece fazer sentido: ao contrário do que afirma Sandburg, as afinidades entre Crane e os modernistas são poucas; apesar do tom muitas vezes irreverente e sarcástico, sua dicção é ainda bem romântica. Assim, convivem no poema em questão expressões carregadas de "poeticidade" tardorromântica, como "affrighted steed" [o corcel temeroso], e passagens que evocam a linguagem brutal da ficção de Crane, como o verso 11. Esse contraste pode sugerir ao leitor desavisado que a utilização do vocabulário mais precioso tenha caráter irônico - uma conclusão que se torna questionável quando se lê o restante da poesia do autor e se constata que a dicção elevada nela ocorre com frequência. Seja como for, nesse poema em particular o choque entre as passagens altissonantes e o realismo cru de alguns versos contribui para o efeito geral do poema, um manifesto antibelicista que critica em particular a glorificação estetizante da guerra. Sob esse aspecto, o poema aponta no mesmo sentido de The Red Badge of Courage, um romance de guerra que ataca as ideias tradicionais de honra e heroísmo em tempo de guerra.

Embora composto em versos livres, "War is kind" se aproxima mais dos padrões formais tradicionais do que a maior parte dos poemas de Crane. Não há exatamente o que Eliot (2014, p. 514) denominava "metro fantasma” - um contrato métrico do qual o poema ora se aproxima, ora se afasta -, mas em alguns momentos a cadência é marcadamente jâmbica ou trocaica, e alguns versos são bem regulares: 2 e 13 são hexâmetros; 3 e 21, pentâmetros; 8 (bem como sua repetição em 19), tetrâmetro. 
Além disso, Crane maneja com destreza outros recursos convencionais, como a rima entre o terceiro e o sexto verso das estrofes pares, que ecoa incompletamente nos vv. 12 e 14 e no refrão-título; as aliterações em $/ \mathrm{h} /$ e rimas em $/ \Lambda /$, dois sons atenuados e discretos, condizentes com a humildade da mãe, contrastando com os encontros consonantais e as vogais longas ressoantes do verso seguinte. Todas essas características fazem de "War is kind" um poema muito pouco representativo da poesia de Crane, revelando um domínio de elementos tradicionais de versificação inglesa que não estão presentes na maior parte da sua poesia.

A tradução acima foi feita há quase trinta anos, quando eu ainda não havia enveredado pelo estudo comparativo dos sistemas métricos do português e do inglês - na verdade, meus conhecimentos de versificação na época eram parcos. ${ }^{2} \mathrm{O}$ que a meu ver justifica reeditar a tradução e apresentar esta análise éa maneira como utilizei, para recriar em português esse poema norte-americano, uma obra do romantismo brasileiro. Percebi, durante o processo de tradução de "War is kind", que um outro texto poético estava interferindo no meu trabalho: "O navio negreiro" de Castro Alves. Não era a primeira vez que eu vivia uma experiência assim: alguns anos antes, ao traduzir uma passagem de um poema de Wallace Stevens, "Sunday morning", senti a interferência de um soneto de Fernando Pessoa (v. BRITTO, 1999). Se, no caso de Stevens, a evocação de Pessoa acabou sendo contraproducente, na tradução de "War is kind" percebi que o poema de Castro Alves poderia me fornecer subsídios úteis. Afinal, Castro Alves era um poeta romântico que empregava um vocabulário "poético" e uma retórica exaltada com intenção crítica: seu alvo específico era o tráfico de escravos. Assim, a situação era de algum modo análoga à de Crane, que também utilizava vocabulário e retórica semelhantes com intenção igualmente crítica, para atacar a glorificação da guerra. Sem dúvida, a analogia não devia ser levada longe demais: o tom de indignação exaltada do "Navio negreiro" não era idêntico à ironia pesada de "War is kind"; mas as semelhanças eram suficientes para que eu pudesse explorar o texto de Castro Alves em busca de elementos que fossem utilizáveis na tradução do poema de Crane. Adiante veremos como se deu essa operação. Na estrofe inicial, porém, o impacto do "Navio negreiro" sobre minha tradução foi

2 Minha tradução de "A guerra é boa” foi publicada na revista Verve (BRITTO, 1990). 
talvez negativo, por ter me levado a me afastar demais do original, no plano métrico. Senão, vejamos:

\begin{tabular}{|c|c|c|}
\hline 5 & 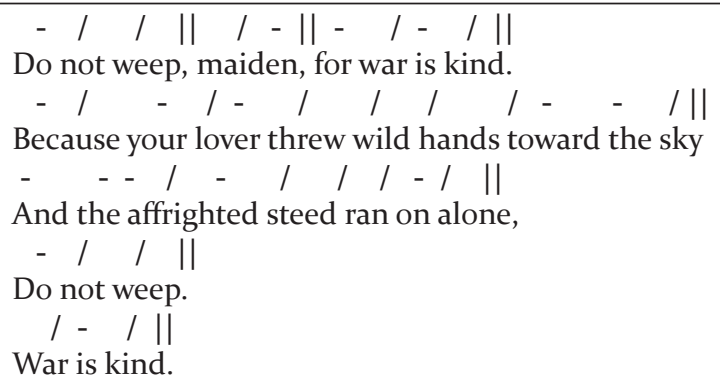 & $\begin{array}{l}-/ /|| /-\|-/ \mid-/\| \\
-/|-/|-/|/ /| /-\mid-/ \| \\
--|-/|-/|/ /|-/ \| \\
-/ / \| \\
/-/ \|\end{array}$ \\
\hline 5 & 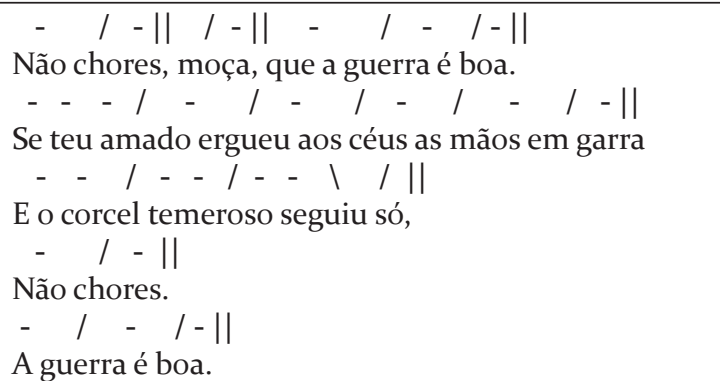 & $\begin{array}{l}-/-\|/-\|-/-/-\| \\
2-4-7-9 \\
---/-/-/-/-/-\| \\
4-6-8-10-12 \\
--/--/--1 / \| \\
3-6-(9)-10 \\
-/-\| \\
2 \\
-/-/-\| \\
2-4\end{array}$ \\
\hline
\end{tabular}

Em Crane, o primeiro verso abre com um pé bastante irregular, seguido de um troqueu; é só no terceiro pé que se afirma o ritmo jâmbico que vai predominar. $\mathrm{O}$ segundo verso é um hexâmetro jâmbico com dois pés irregulares (o $4^{\circ}$ e o $\left.5^{\circ}\right)$; o terceiro é um pentâmetro com pés irregulares na $1^{\underline{a}}$ e $3^{\underline{a}}$ posições; o quarto e o quinto são fragmentos que não admitem subdivisão. Dos 17 pés da estrofe, pois, nada menos que 8 - quase a metade - fogem ao padrão jâmbico. Já a tradução, possivelmente por ter sido influenciada pela minha leitura paralela do poema de Castro Alves, é metricamente bem mais regular que o original. $O$ primeiro verso é um eneassílabo de ritmo jâmbico quase totalmente regular, que se transforma num decassílabo sáfico, se for feito um hiato (um tanto forçado, é verdade) entre "que" e "a". O v. 2 é um alexandrino romântico; o 3, um decassílabo martelo-agalopado; e os dois versos fragmentários ao final da estrofe são perfeitamente jâmbicos. Observe-se que não consegui reproduzir a rima incompleta entre o v. 2 e os vv. que abrem e fecham a estrofe, um problema que vai se repetir ao longo de toda a tradução. 


\begin{tabular}{|c|c|c|}
\hline 10 & $\begin{array}{l}\text { / I / }- \text { / }--/--\| \\
\text { Hoarse, booming drums of the regiment, } \\
/-/ \\
\text { Little souls who thirst for fight, } \\
-\quad / \\
\text { These men were born to drill and die. } \\
--\quad /\end{array}$ & $\begin{array}{l}/\|/-|/-|-/ \mid--\| \\
/-|/-| /-|/| \mid \\
-/|-/|-/|-/| \\
--|-/| /-|/-| /-|| \\
/-|-/|-|||/-|-/-\| \\
-/|--/|-/|-/| \mid\end{array}$ \\
\hline 10 & 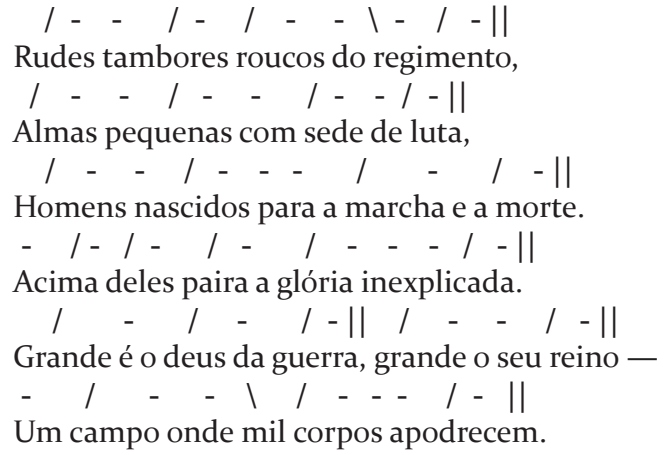 & $\begin{array}{l}|--/-/--|-/-\| \\
1-4-6-(9)-11 \\
\mid--/--/--/-\| \\
1-4-7-10 \\
\mid--/---/-/-\| \\
1-4-8-10 \\
-/-/-/-/---/-\| \\
2-4-6-8-12 \\
/-/-/-\|/--/-\| \\
1-3-5-7-10 \\
-/--\mid /---/-\| \\
2-(5)-6-10\end{array}$ \\
\hline
\end{tabular}

A segunda estrofe de "War is kind" mistura ritmos diferentes. O v. 6, o primeiro da estrofe, não tem um padrão definido; o v. 7 é trocaico e o 8 é jâmbico, ambos rigidamente metrificados, como se para evocar a cadência maquinal do drill ("ordem unida"); os demais são irregulares. Por outro lado, observamos que todos os versos têm quatro acentos primários, o que não deixa de ser uma característica métrica unificadora da estrofe. Na minha tradução, os vv. 7, 8, 10 e 11 têm dez sílabas - o 7 é uma gaita-galega; o 8, um sáfico; o 10, um decassílabo com um padrão de acentuação irregular; o 11, um heroico. Os demais versos da estrofe se afastam do padrão decassilábico, mas não muito: o v. 6 tem onze sílabas, e o 9 é mais um alexandrino romântico. O efeito de rigidez rítmica dos vv. 7 e 8 do original não se repete na tradução, ainda que o alexandrino em 9 seja quase perfeitamente jâmbico. Assim, se a estrofe original tem como referencial a medida de quatro acentos por verso, a base da estrofe traduzida é o decassílabo. No plano dos fonemas, o único efeito que se conseguiu reproduzir foi a aliteração drill-die, que reaparece como "marcha"-"morte" - o que na verdade implica uma perda, na medida em 
que a bilabial / $\mathrm{m} /$ está longe da contundência da oclusiva /d/ do original. A rima completa entre os vv. 8 e 11 se perdeu.

\begin{tabular}{|c|c|c|}
\hline 15 & 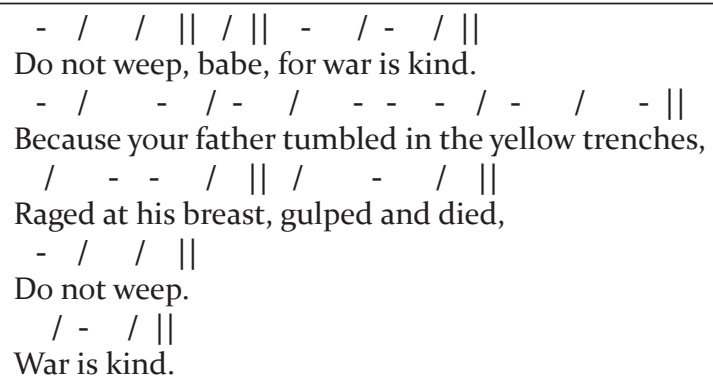 & $\begin{array}{l}-/ /\|/\|-/ \mid-/ \| \\
-/|-/|-/|--|-/|-/|-\| \\
/-|-/||/-/| \\
-/ / \mid \\
/-/ \mid\end{array}$ \\
\hline 15 & 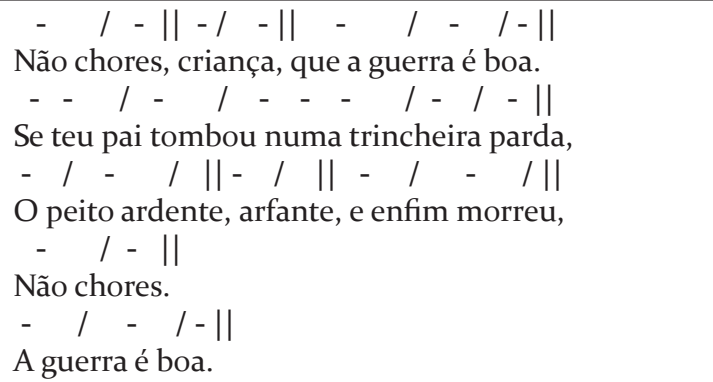 & $\begin{array}{l}-/-\|-/-\|-/-/-\| \\
2-5-8-10 \\
--/-/---/-/-\| \\
3-5-9-11 \\
-/-/\|-/\|-/-/ \| \\
2-4-6-8-10 \\
-/-\| \\
2 \\
-/-/-\| \\
2-4\end{array}$ \\
\hline
\end{tabular}

A terceira estrofe é uma variante da primeira, e cada verso seu é de tamanho semelhante ao de sua contraparte da primeira estrofe, com exceção do v. 14, que é bem mais curto. Aqui a tradução está um pouco mais irregular: o v. 12 é um decassílabo anômalo, com acento na $5^{\mathrm{a}}$, e o v. 13 um hendecassílabo sem ritmo definido. Mas o v. 14 é um decassílabo jâmbico perfeito, bem distante da irregularidade do verso que ele traduz. Novamente, perdeu-se a rima incompleta que havia no original entre o v. 14 e o primeiro e último versos da estrofe. Observe-se que no plano semântico houve um desvio significativo no v. 13, em que yellow foi traduzido como "parda" - creio que por considerações de ordem métrica. 


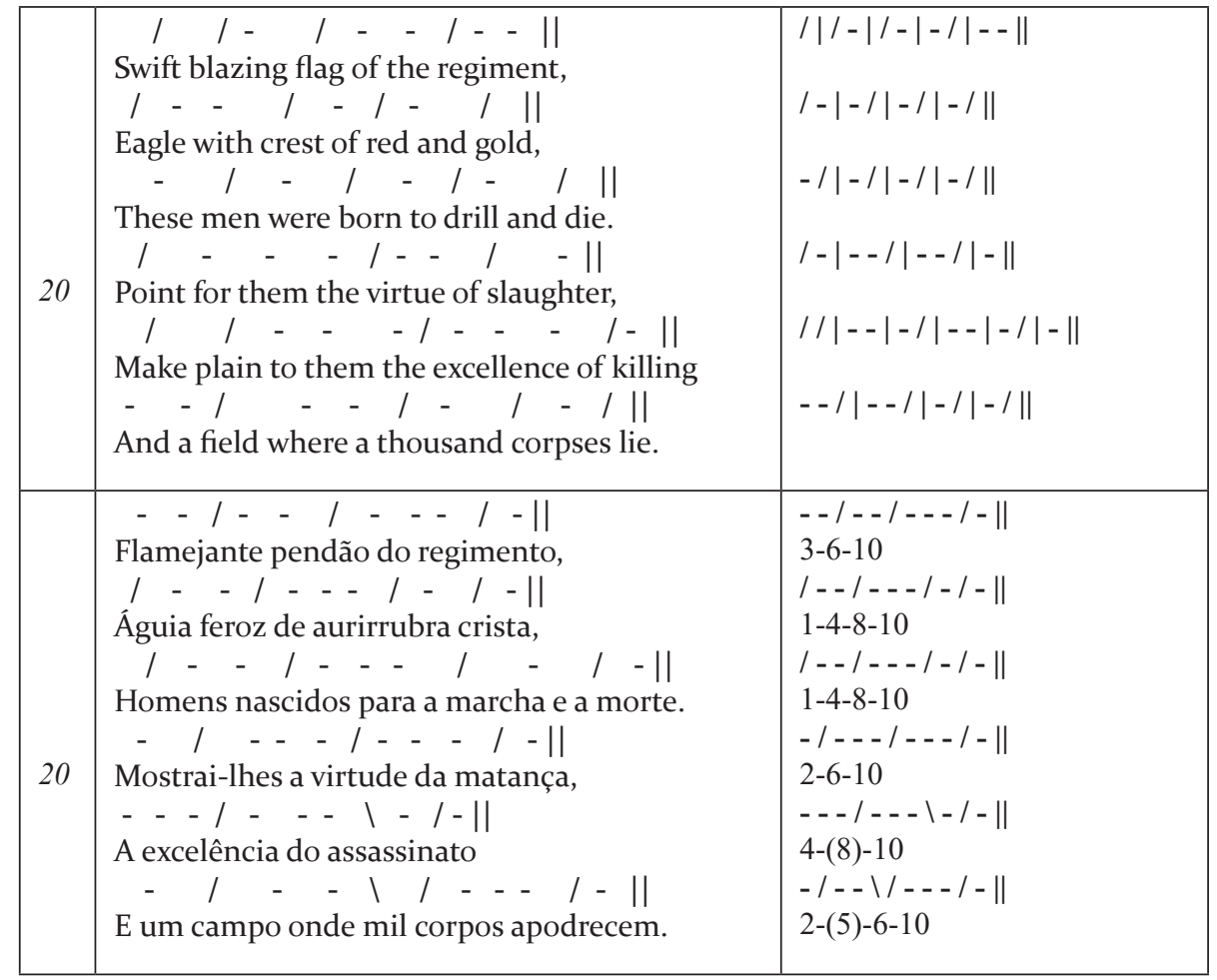

Assim como a terceira estrofe é uma variante da primeira, a quarta deriva da segunda: os vv. 19 e 22 são praticamente idênticos aos vv. 8 e 11, e o verso inicial das duas estrofes termina com "of the regiment". Com exceção do v. 20, todos os versos têm exatamente quatro acentos, e há um predomínio discreto do ritmo jâmbico - dos 25 pés da estrofe, 12 são jambos.

Foi nessa estrofe em que o paralelo com o poema de Castro Alves me pareceu mais evidente. As duas passagens que me saltaram à vista foram estas:

Swift blazing flag of the regiment, Eagle with crest of red and gold,
Auriverde pendão de minha terra, Que a brisa do Brasil beija e balança, Estandarte que a luz do sol encerra, E as promessas divinas da esperança... (CASTRO ALVES, 1986, p. 283)

Em ambos os poemas havia uma menção a bandeiras, com referência a suas cores, utilizando uma linguagem elevada, imediatamente antes da 
condenação peremptória da cena descrita - no caso de Crane, a bandeira é levada pelo batalhão ao campo de batalha; no de Castro Alves, a bandeira é desfraldada pelo navio negreiro. Observe-se como o recurso retórico utilizado por Crane é passar bruscamente do registro elevado para um tom sarcástico, culminando com uma descrição fria, enquanto Castro Alves se mantém no plano retórico do sublime, apenas substituindo o louvor pelo vitupério:

These men were born to drill and die.

Point for them the virtue of slaughter,

Make plain to them the excellence of killing

And a field where a thousand corpses lie.

Tu, que da liberdade após a guerra, Foste hasteado dos heróis na lança, Antes te houvessem roto na batalha, Que servires a um povo de mortalha!...

Na minha tradução da passagem, os elementos tomados emprestados ao "Navio negreiro" são vários. No plano do vocabulário, flag foi traduzido como "pendão", e red and gold foi vertido como "aurirrubra", termo composto calcado em "auriverde". A sintaxe privilegia a ordem adjetivo-substantivo - "flamejante pendão", "aurirrubra crista" - queécaracterística do registro elevado. Quanto à métrica, pode-se dizer que aqui minha tradução está mais próxima do poema de Castro Alves do que do original. Os três versos iniciais da estrofe são decassílabos perfeitos - um martelo-agalopado seguido de dois sáficos com idêntica pauta acentual. Porém a rima completa entre os vv. 19 e 22 , tal como a que havia entre os versos correspondentes da segunda estrofe, mais uma vez se perdeu.

\begin{tabular}{|c|c|c|}
\hline 25 & 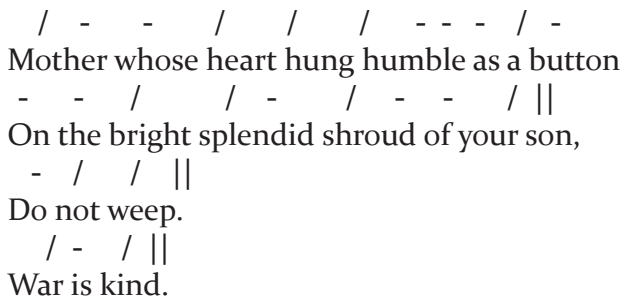 & $\begin{array}{l}|-|-/|/ /|--|-/|- \\
--|/ /|-/|--/| \mid \\
-/ /|| \\
/-/ \|\end{array}$ \\
\hline 25 & 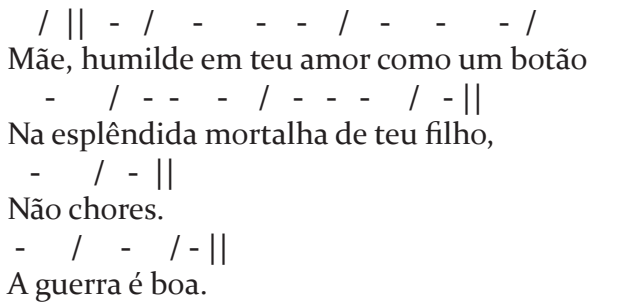 & $\begin{array}{l}/ \|-/---/---/ \\
1-3-7-11 \\
-/---/---/-\| \\
2-6-10 \\
-/-\| \\
2 \\
-/-/-\| \\
2-4\end{array}$ \\
\hline
\end{tabular}


A estrofe final, embora termine com o par de versos fragmentários que, funcionando como refrão, fecha as duas estrofes de número ímpar anteriores, não repete o padrão delas: são apenas quatro versos ao todo, e os dois versos iniciais não começam com "Do not weep" e "Because your". A primeira estrofe dirige-se à moça que perdeu o namorado; a terceira, à criança que perdeu o pai; a estrofe final, à mãe cujo filho morto está sendo velado. Aqui os versos são bem irregulares: não há um número de acentos fixo em cada verso, nem tampouco predomina algum pé, a ponto de a análise em pés se tornar questionável. Como já foi observado, aqui é no plano das aliterações e assonâncias que se concentram os efeitos: Crane contrasta habilmente as ocorrências dos sons atenuados $/ \mathrm{h} / \mathrm{e} / \Lambda /$ no v. $23 \mathrm{com}$ a sonoridade mais intensa dos encontros consonantais /br/ e / $\mathrm{spl} /$ e das vogais longas /ai/ e /av/ no verso 24, o que reforça o contraste semântico entre humble e button, de um lado, e bright e splendid, do outro. Observe-se que o /as/ de bright funciona como uma assonância com a ocorrência final de kind. Na tradução, os dois versos longos são na verdade mais regulares do que a escansão dá a entender: se eliminarmos a sílaba inicial do v. 23 - "Mãe", separada do restante do verso por uma pausa -, teremos na verdade dois decassílabos heroicos de corte bem tradicional, com acentos na segunda e na sexta sílabas. A solidez da estrutura métrica em parte compensa a perda dos efeitos fonológicos: claramente, o contraste entre os /m/ do v. 23 e o encontro consonantal / $\mathrm{pl} /$ do verso seguinte não chegam a recriar com a mesma ênfase o efeito do original; porém destaque-se que a estrutura proparoxítona de "esplêndida" faz com que a palavra não contraste apenas no plano do sentido com "humilde", mas também no plano acentual. Mais uma vez, perdeu-se a rima com a palavra final do refrão.

A análise dessa tradução de "War is kind" mostra, a meu ver, as vantagens e os perigos de buscar recursos para a tradução poética num poema já existente na língua-meta. Porém é bom lembrar que talvez haja um outro motivo para a tradução ter saído mais regular que o original, no plano da métrica: a conhecida tendência que têm os tradutores para a regularização do original. Trata-se de um fenômeno análogo ao que Berman (2013, pp. 68-70) denominou "racionalização": o tradutor é levado a reestruturar o texto, ao traduzi-lo, de modo a conformá-lo "a uma certa ideia da ordem de um discurso". No caso do texto poético, essa ideia de ordem muitas vezes passa pela estrutura métrica do poema. Até mesmo para o tradutor mais calejado, por vezes é difícil resistir à tentação de um 
decassílabo sáfico perfeito que se insinua como versão possível de um verso que, no idioma original, não segue nenhum contrato métrico definido. No caso em questão, a interferência do poema de Castro Alves parece ter tido o efeito de reforçar essa tendência.

\section{THE TRANSLATION OF A POEM BY STEPHEN CRANE}

Abstract: The article analyzes the author's translation of a poem by Stephen Crane, and discusses the use in the translation of rhetorical, lexical, and formal resources found in a poem by Castro Alves.

Keywords: Stephen Crane; Castro Alves; Poetry Translation.

\section{REFERÊNCIAS}

BERMAN, Antoine. A tradução e a letra ou o albergue do longínquo. Trad. Marie-Hélène C. Torres, Mauri Furlan e Andreia Guerine. 2. ed. Tubarão/Florianópolis: Copiart/ PGET/UFSC, 2013[1985].

BRITTO, Paulo H. Tradução e criação. Cadernos de Tradução (UFSC), v. 1, n. 4, 1999, pp. 239-262. Disponível em: <http://www.periodicos.ufsc.br/index.php/traducao/ article/view/5534/4992>.

CASTRO ALVES, Antônio F. de. O navio negreiro. In: CASTRO ALVES, Antônio F. de. Obra completa. Rio de Janeiro: Nova Aguilar, 1986[1869, 188o].

CAZEMAJOU, Jean. Stephen Crane. Minneapolis: University of Minnesota Press, 1969.

CRANE, Stephen. War is kind. In: The Collected Poems of Stephen Crane. Nova York: Knopf, 1965[1899], pp. 77-78.

CRANE, Stephen. A guerra é boa. Trad. Paulo H. Britto. Verve, maio, 1991.

ELIOT, T. S. Reflections on vers libre (1917). In: The Complete Prose of T. S. Eliot: The Critical Edition. V. 1: Apprentice Years, 1905-1918. Baltimore/Londres: Johns Hopkins University Press/Faber and Faber, 2004. 